\title{
A HISTÓRIA CRUZADA E OS LIMITES DO COMPARATIVISMO HISTÓRICO
}

\author{
Entangled history and the limits of \\ historical comparativism
}

Isabela Albuquerque*

\begin{abstract}
Resumo: Este artigo tem por objetivo abordar algumas considerações sobre a história comparada enquanto campo historiográfico, desde as contribuições de Marc Bloch na década de vinte do século passado. Ao analisar a trajetória da história comparada, consideramos as vantagens do método comparativo e a delimitação dos objetos a serem comparados. A partir da década de oitenta do século passado, o comparativismo tradicional que buscava semelhanças e diferenças entre as sociedades dava lugar a uma nova modalidade: as histórias conectadas, que privilegiavam análise dos objetos a partir do intercâmbio e do contato entre as sociedades. A história cruzada representa uma dessas mudanças nos paradigmas sobre o comparativismo histórico. A proposta de Werner e Zimmermann para o cruzamento - de objetos, conceitos, escalas - desafia historiadores a repensar o fazer historiográfico dentro da história comparada, excedendo os antigos limites da disciplina.

Palavras-chave: História comparada; histórias conectadas; história cruzada
\end{abstract}

\begin{abstract}
This paper aims to approach some considerations on comparative history as a historiographic field, since the contributions of Marc Bloch in the twenties in the past century. By analyzing the path of comparative history, we consider the advantages of comparative method and the delimitation of objects to be compared. Starting from the eighties, the traditional comparativism which seeks similarities and differences between societies - is replaced by new modality: shared history, which privileges analyzing objects through societies' exchanges and contacts. Entangled history represents one of these changes in historical comparativism paradigms. Werner and Zimmermann's proposal for entanglement - of objects, concepts, scales - defies historians to rethink their historiographical process inside comparative history, exceeding the old boundaries of the discipline.
\end{abstract}

Keywords: Comparative history - shared histories - entangled history

\section{A história comparada enquanto campo historiográfico}

O ato de comparar é inerente ao ser humano, mesmo que seja única e exclusivamente para fins de aproximar uma realidade supostamente estranha a outra com a qual estamos mais familiarizados. Políbio (203 a.C. - 120 a.C.), por exemplo, ao abordar as questões relativas à guerra entre romanos e cartagineses, utilizou-se do comparativismo para tecer suas análises. (Hannick, 2001) É evidente que as obras do historiador grego não tinham preocupação com questões historiográficas ou quaisquer pretensões de metodológicas no que tange ao ato de comparar.

\footnotetext{
* Doutora em História Comparada pelo PPGHC/UFRJ e professora colaboradora do Curso de Especialização em História Antiga e Medieval (CEHAM) da UERJ. E-mail: isabela.albuquerque16@gmail.com
} 
Debatida entre os pesquisadores que se utilizam dessa modalidade, a história comparada foi abordada na condição de método e de campo historiográfico. Todavia, o método comparativo consiste para o historiador em mais do que simplesmente buscar melhor compreender um contexto histórico que não o dele ou que meramente aproximar períodos distintos. Comparar, apesar de ato intuitivo frente às situações novas que muitas vezes nos são apresentadas, é também uma forma específica de propor e refletir acerca de questões. (Barros, 2007)

Apesar de profícuo na aproximação de contextos distintos, o campo da história comparada pode conter também armadilhas ao pesquisador e cabe ressaltar aqui duas questões importantes: o que comparar e como fazê-lo? De acordo com Haupt, essas questões derivam do fato de "a história comparada não oferecer uma metodologia confirmada" (Haupt, 1998) e, caso não delimitemos o que pode ser "comparável", podemos incorrer no erro grave do anacronismo, estabelecendo, assim, comparações inconsistentes. ${ }^{1}$ Contudo, ao longo da última década, a História Comparada tem buscado delimitar melhor sua forma de ação e os mecanismos de sua utilização de maneira mais precisa dentro da pesquisa histórica.

Marc Bloch (1886-1944), considerado quase que por unanimidade como o precursor do método comparativo em História, já apontava a importância em se fazer uso do método. Para o medievalista francês, era preciso romper com os paradigmas da velha história política do século XIX, a qual, na prática, acabava por acirrar ainda mais os ânimos entre as Estados europeus com discursos enaltecendo seus nacionalismos. Ao destacar a utilidade do comparativismo histórico, Bloch destacou as vantagens desta modalidade que, para além das semelhanças que poderiam ser encontradas entre duas sociedades, buscava também as diferenças que acabavam por vezes a saltar aos olhos. Estas, inclusive, eram mais interessantes, segundo o medievalista francês, de serem analisadas, pois desnudavam a peculiaridade do processo histórico. (Bloch, 1998). O pesquisador, ao invés de buscar padrões que se repitam nas sociedades humanas, deve achar mais instigante primar pela originalidade e pela singularidade, pistas deixadas às quais o ogro historiador deve seguir.

Inicialmente, Bloch levanta duas formas de comparação: a análise de sociedades diacrônicas - em tempos históricos distintos - e de sociedades sincrônicas - situadas num mesmo tempo histórico. Apesar de não preterir uma pela outra, o pesquisador francês afirma que a grande vantagem desta segunda modalidade de comparativismo na História reside na possibilidade de discernirmos as influências exercidas de um grupo sobre outro (Bloch, 1998), pois, afinal, situarem-se em um mesmo tempo histórico possibilitaria uma interação entre ambas.

A comparação de sociedades sincrônicas seria preferível à diacronia (Theml e Bustamante, 2007), pois, ao comparar sociedades diacrônicas, deve-se tomar cuidado extra para não "forçar" modelos explicativos, a fim de encaixá-los em suas comparações, gerando, ao final, explicações generalizadas ou errôneas. O cuidado com o estabelecimento do que Marcel Detienne chamou de comparáveis ${ }^{2}$ deve ser um dos primeiros cuidados do pesquisador.

${ }^{1} \mathrm{Em}$ seu artigo Uses of comparative history in macro social inquiry, Theda Skocpoland Margaret Somers, professoras e pesquisadoras das Universidades de Harvard e Michigan, respectivamente, defendem que há três tipologias principais de comparativismo histórico: 1) análise macro-causal(ao abordar a respeito das inferências causais numa perspectiva macro, com relação às estruturas e processos); 2) teoria da demonstração paralela (quando se busca identificar se uma hipótese ou uma teoria repetem-se em situações diversas e contextos distintos) e 3) contrastes de contextos (ao contrapor situações diversas e expor que há semelhanças e diferenças, estas as quais enriquecem o processo histórico). Para maiores referências, consultar SKOCPOL, Theda and SOMERS, Margaret. The Uses of Comparative History in Macro social Inquiry. In: Comparative Studies in Society and History, Vol. 22, No.2 (Apr., 1980), 174-197.

2 Marcel Detienne em seu livro Comparar o incomparável aborda a importância em se estabelecer de maneira clara, objetiva e bem delimitada o recorte dos objetos de estudo a serem comparados. Na visão do 
De acordo com o historiador alemão Jürgen Kocka afirma que comparar em História significa discutir dois ou mais fenômenos históricos sistematicamente a respeito de suas similaridades e diferenças de modo a se alcançar determinados objetivos intelectuais, os quais podem ser agrupados em propósitos heurísticos, descritivos, analíticos e paradigmáticos. Tal assertiva denota o potencial metodológico da História Comparada como um campo rico e amplo, com uma gama de opções a serem exploradas, iluminando questões e/ou problemas que, de outra forma, poderiam ser negligenciados (Kocka, 2003).

No entanto, comparar requer certos cuidados. Na visão Barros

É preciso distinguir perfeitamente a boa da má analogia; a generalização aceitável, da camisa de força em que são mal acomodadas sociedades e experiências históricas dotadas de singularidades que as fazem únicas; a aparência similar que apresentam alguns processos, de suas motivações mais profundas (por vezes territórios de diferenças fundamentais que a mera aparência factual costuma ocultar). (Barros, 2007)

O método comparativo em história, portanto, nos apresentaria uma série de análises possíveis, as quais poderiam se perder, serem negligenciadas e até mesmo fechadas nas fronteiras do Estado Nação, cujo objetivo era entender e (re)contar apenas a história oficial de seus países. A história comparada transcenderia os limites físicos e ideológicos dos Estados Nacionais, abrindo o diálogo e buscando novos comparáveis.

$\mathrm{Na}$ verdade, esta justificativa para o método comparativo em história não é algo que se aplique à realidade da academia brasileira, haja vista que os nossos programas de pós-graduação em história não centram suas pesquisas apenas em temas relacionados diretamente ao Brasil - e este é o caso, inclusive, de nosso trabalho. A história comparada apresenta, portanto, um campo muito maior de possibilidades de análise do que simplesmente contrapor objetos similares e distintos ao historiador.

De acordo com Ciro Cardoso e Hector Brignoli, o método comparativo exerceria um papel importante no questionamento de modelos prévios de explicações históricas, trazendo um objeto à nova luz ou a novas problemáticas (Cardoso e Brignoli, 1981). Explicações já consolidadas muitas vezes tendem a não serem revistas e é aí que a comparação ocupa um papel importante. Ao confrontar sociedades distintas, o historiador pode confirmar, via método comparativo, se as variáveis consideradas na explicação de dado fenômeno histórico realmente corroboram um modelo explicativo válido. Todavia, seus objetos de pesquisa e problemáticas devem ser muito bem delimitados, do contrário, o historiador pode incorrer no anacronismo, invalidando, assim, sua pesquisa. (Cardoso e Brignoli, 1981)

Sobre essa questão, Rüsen afirma

Toda comparação precisa de um parâmetro organizativo. Antes de olhar para os materiais (textos, tradições orais, imagens, rituais, monumentos, assim por diante), é necessário saber que campo de coisas deve ser levado em consideração e de que maneira as descobertas nesse campo devem ser comparadas. Trocando em miúdos: quais são as similaridades e onde estão as diferenças nos domínios da historiografia? (Rüsen, 2006)

Como podemos observar, para que tal metodologia seja útil e viável para a história não

pesquisador francês, ainda, a comparação diacrônica é perfeitamente possível, desde que estas ações sejam bem executadas. 
basta apenas comparar, mas devem-se buscar também elementos que possam ser passíveis de comparação. Meramente encaixar modelos explicativos generalizantes não dá conta de problemáticas específicas.

Acrescentando à nossa discussão acerca de eleger o que é comparável, Kocka enfatiza que não se podem comparar totalidades, mas determinados aspectos das sociedades, pois o contexto tem de estar presente de maneira sérias nas operações intelectuais do historiador (Kocka, 2003). Posto isso, seria metodologicamente inviável compararmos sociedades inteiras ou recortes demasiado largos (a economia, a política, a sociedade, a cultura). Para tanto, seria mais prudente uma comparação que trate de determinados aspectos que permeiam a política ou a economia ou a sociedade ou a cultura. Recortes muito abrangentes tendem a produzir explicações reducionistas, que não levam em conta as especificidades dos processos históricos dentro de cada contexto comparado.

\section{Histórias conectadas: da revisão da história comparada à história das transferên- cias}

As três últimas décadas vivenciaram intensos debates dentro da história comparada, sobretudo dentro do círculo de relativamente estreito entre historiadores sociais e germanistas. Desde Marc Bloch, nos idos dos anos 20, o comparativismo histórico esteve diretamente ligado a comparar Estados Nacionais e a buscar semelhanças e dessemelhanças entre eles, no intuito de demonstrar que, antes de serem ingleses, franceses ou alemães, os agentes históricos eram, na verdade, herdeiros de uma mesma tradição, muito mais do que imaginavam. O objetivo de Bloch era desconstruir um pouco a ideia do Nacionalismo e buscar aproximações entre as sociedades europeias. A construção das comparáveis dentro da história comparada passava necessariamente, portanto, pelo viés do Estado Nação enquanto construção lógica, mesmo que isso ocorresse apenas para criticá-la.

Muito além de observar similaridades e diferenças em objetos recortados, as histórias conectadas estão mais interessadas nos processos de influência recíproca e mútua entre regiões diversas. Tais percepções recíprocas e assimétricas, são interpretadas como parte integrante de uma história una, construída a partir do cruzamento. Mais interessante do que pesar as similaridades e diferenças entre Europa e Mundo Árabe, por exemplo, seria pensar as influências que um exerce sobre o outro. (Kocka, 2003).

Após o fim do conflito Leste-Oeste e com a influência dos estudos pós-coloniais, houve o aumento do interesse em abordagens comparativas transnacionais. A partir de finais dos anos 80, o modelo comparativo via Estado Nação veio sendo revisto e novas modalidades dentro do comparativismo histórico levaram-nos a (re)pensar a construção de nossos objetos de pesquisa, seus respectivos recortes e a própria forma do fazer historiográfico. Uma multiplicidade de novos termos que abordam a história cultural passou a fazer parte do universo da história comparada. (Charle, 2010)

Contudo, José D'Assunção Barros afirma que esta nova tendência dentro da história comparada se encontra no momento em disputa intelectual, pelo reconhecimento e afirmação de seus respectivos campos historiográficos. Não há ainda uma padronização adotada com relação aos novos aportes metodológicos, o que por vezes pode gerar inclusive certa confusão.

Entrementes, a verdade é que parece haver uma certa disputa e territorialização, no campo de 
saberes contemporâneos, em torno dessas designações; nem sempre elas representam efetivamente experiências tão distintas, apesar dos manifestos que seus líderes procuram dirigir uns contra os outros à maneira de demarcar seus territórios acadêmicos. Como apresentam-se as novas modalidades relacionais no mapa dos atuais saberes historiográficos e de seus lugares institucionais? (Barros, 2014)

Procuramos traçar o perfil de dois desses supostos novos aportes metodológicos, dentro do que Barros chamou em seu artigo de Histórias Conectadas e seus procedimentos relacionais ao longo do texto. Histórias transnacionais, histórias interconectadas, histórias entrelaçadas e histórias cruzadas, com propostas metodológicas bastante próximas, travam uma disputa por quem permanecerá no vocabulário historiográfico no futuro. ${ }^{3}$

Em nosso artigo, buscamos focar nas modalidades traduzidas para a língua portuguesa como história das transferências, proposta por Michel de Espagne, e história cruzada de Michael Werner e Bénédicte Zimmermann, em função do papel preponderante que ambas desempenharam nesta empreitada de revisão dos pressupostos dentro da história comparada. (Hartmunt, 2004) Além disso, não passa despercebido por nós o devido enfoque dado aos intercâmbios entre as sociedades e ao cruzamento - de pontos de vista, objetos e escalas - enquanto ferramentas válidas na construção de uma problemática de pesquisa.

É evidente que a utilização destes novos aportes está diretamente ligada às demandas do período em que surgiram. O medo da globalização, a desaceleração da economia europeia - frente ao Sudeste Asiático e ao Japão - o desemprego e o interesse dos intelectuais europeus no final do século XX pela União Europeia ajudam-nos a entender porque a história das transferências e a história cruzada passaram a substituir o modelo clássico de comparativismo histórico. (Kaelble, 2004) O Estado Nacional já não era mais a única comparável possível e plausível num mundo globalizado, no qual as conexões se davam cada vez mais rápido e o nacionalismo parecia perder força frente a tantas demandas identitárias e de cunho separatista. Somando-se a isso, as migrações humanas dos continentes asiático e africano proporcionavam ao continente europeu Estados cada vez mais plurais, o que tornava até mesmo fora de moda abordar essas nações como constructos homogêneos.

Michel de Espagne, germanista, diretor de pesquisa no CNRS, responsável pela Unidade Mista de Pesquisa: Países Germânicos e também pelo Laboratório TransferS (ENS-CNRS-Collège de France), centra a maior parte de suas pesquisas nas relações entre franceses e alemães. Sobre a metodologia comparativa em História, Espagne afirma que

Comparar dois objetos significa opô-los para enumerar suas semelhanças e suas diferenças e,
por meio de um deslizamento inevitável, petrificar as oposições. Com efeito, é possível com-
parar apenas o que não se confunde. Quando se compara um grupo social na França e na
Alemanha, parte-se do pressuposto de que o pertencimento nacional não pode deixar de ser
um traço pertinente; tal conclusão resta interditada. A comparação reforça a clivagem nacional
e torna problemática colocá-la em questão. (Espagne, 2013).

Mesmo valendo-se do Estado Nacional como unidade de comparação, Espagne tem plena consciência de que esta não é o único viés válido ou possível e que se deve tomar cuidado para que

\footnotetext{
${ }^{3}$ Em língua inglesa, essas novas modalidades de história comparada intitulam-se shared, entangledou g/obal history. Apesar da falta de consenso quanto à nomenclatura acadêmica, optamos por seguir a proposta de Barros como histórias conectadas para designar a modalidade que abarca tanto a história das transferências quanto a história cruzada.
} 
comparar não seja um engessamento forçoso da realidade. O simples fato de se considerar comparar unidades dentro de Estados Nacionais já nos sugere estruturas e instituições - que são enxergadas muitas vezes por nós como naturais - e não necessariamente como as experiências de tais grupos na história. (Kaelble, 2004) Os Estados Nacionais também são fruto de um processo histórico e, muito embora suas instituições sociais pareçam de relance sempre ter existido, não podemos perder de vista que estes foram construídos e forjados dentro da história e não existem a priori como categorias autônomas. Tal constatação, contudo, não significa invalidar o uso do Estado Nação como comparável, todavia lembrar de que ele não é o único.

É justamente dentro desta premissa que Espagne cunha o termo transferência. Como o próprio autor afirmou, "A teoria das transferências culturais concebe-se como contribuição a uma correção metodológica do comparativismo em história cultural.” (Espagne, 2013) A história das transferências apresenta como propósito, portanto, rever os caminhos que a história comparada tem tomado até agora, sobretudo com relação à construção de suas comparáveis.

Espagne propõe que seria mais profícuo, ao invés de se procurar observar categorias sociais de uma nação e de outra para depois compará-las, buscar as imbricações dentro do processo histórico que permitiram a formação daquele grupo enquanto tal. Em outras palavras, a história comparada deveria averiguar as influências sofridas de um grupo para outro no percurso histórico, e não estabelecer os Estados Nacionais como parâmetros naturais para a comparação. Com isso, o binômio semelhança-diferença deixou de ser o enfoque principal da história comparada, dando lugar às interações entre os sujeitos e em como suas relações foram construídas.

Sobre o conceito de transferência. Espagne entende como sendo "as transformações que ocorrem no momento da transmissão de conceitos, normas, imagens e representações de uma cultura para outra", as quais podem se dar por meio de encontros ou de leituras realizadas de uma cultura por outra. Enquanto a comparação clássica centra sua análise em estruturas e instituições, a transferência privilegia a experiência dentro da história (Kaelble, 2004).

Ao abordar a questão da transferência, Espagne traz outro referencial caro dentro da ciência histórica: o tempo. O historiador francês afirma ainda que "Só a dimensão do tempo pode explicar as diferenças estruturais.”. (Espagne, 2013) A história desenrola-se no tempo e é justamente considerando-o como uma variável primordial que o pesquisador encontra as mudanças sofridas dentro das sociedades, pode determinar quando esta ocorre e o momento em que acontece a transmissão de uma cultura para a outra. O tempo deixa de ser um mero coadjuvante, legado apenas a situar quando os fenômenos ocorrem, e passa a ser o protagonista para o entendimento e o desenrolar do processo histórico estudado. A medida não é simplesmente contextualizar "o que acontece e quando acontece", mas não perder de vista a razão primeira por que tais transformações ocorrem, cerne e matéria prima do oficio do historiador.

Recortar objetos de pesquisa de maneira meramente formal, portanto, pode prender o historiador dentro das fronteiras do Estado Nação, sendo mais interessante observar as influências que um grupo social exerce sobre o outro. $\mathrm{O}$ método proposto por Espagne tem como objetivo primeiro extrapolar as análises para além das comparáveis próprias aos Estados Nacionais ${ }^{4}$.

\footnotetext{
${ }^{4}$ É importante esclarecer que não estamos fazendo uma crítica descontextualizada à comparação de elementos dentro do Estado Nacional. Nos anos 20 do século passado, quando Marc Bloch "inaugurou" o método comparativo dentro da História com o lançamento de Os Reis Taumaturgos em 1924, o nacionalismo exacerbado, herdeiro do século XIX, ainda dificultava o diálogo e a aproximação entre nações historicamente rivais. A proposta de Bloch de estabelecer elementos que aproximavam e afastavam os Reinos da Europa Medieval, além de ser metodológica era também política, pois não visava exclusivamente a análise da taumaturgia pelos reis franceses e ingleses, mas também destacar que a trajetória histórica de
} 
Apesar de já ser um campo historiográfico dentro do comparativismo histórico que vem adquirindo cada vez mais terreno desde o final dos anos 80, a bibliografia em língua portuguesa ainda é bastante escassa, limitando-se a traduções de revistas majoritariamente provenientes de Alemanha e França. ${ }^{5}$

\section{História cruzada: velhos problemas, novas abordagens}

A história cruzada, proposta por Michael Werner e Bénédicte Zimmermann, levantou novas questões acerca da forma como os objetos de pesquisa e as fontes eram abordados pela ciência histórica. O conceito de cruzamento tem como proposta ir além das comparações e transferências, referindo-se a novas leituras, princípios e investigações plurilaterais (Kaelble, 2004). O momento em que os autores lançam seu manifesto sobre o tema, esteve marcado por um período de transformações, no qual "Ao relativizar as antigas certezas e dar lugar a novas formas de posicionamento dentro das áreas do saber", (Werner e Zimmerman, 2003) este campo dentro da história comparada convida os pesquisadores a olharem com mais cuidado seus objetos de pesquisa, fazendo-os repensar como estes eram construídos e abordados. A ideia de crų̧ar - croiser, em francês - significa não apenas fazê-lo com informações ou contextos, mas também em nível intelectual, incentivando o diálogo com outras áreas do saber.

O cruzamento se dá assim como uma atividade cognitiva estruturante que, por diversas operações de enquadramento, constrói um espaço de compreensão. Através dele, é um processo cognitivo articulando objeto, observador e ambiente que se abre. O cruzamento das escalas espaciais e temporais, que tanto pode ser intrínseco ao objeto como o resultado de uma opção teórica ou metodológica, é um exemplo particularmente revelador desta imbricação entre as dimensões empírica e reflexiva. (Werner e Zimmerman, 2003)

É justamente a partir do que os autores chamam de cruqamento que esta modalidade da história comparada se assenta. Primeiramente, é imprescindível identificar que este só pode ser feito mediante uma ancoragem empírica, ou seja, diretamente relacionado à pesquisa histórica e considerando suas variáveis específicas, ou seja, não existe cruzamento dado ou a priori. Este só é realizado a partir do momento em que se elegem o contexto e o(s) objeto(s), posto que só se pode construir esta teia de explicações dentro da especificidade de cada processo histórico. No caso da história cruzada, as interseções produzidas pelo cruzamento, seja ele no objeto, no ponto de vista ou em escalas, são as engrenagens base para a construção do objeto.

Esta metodologia comparativa traz também novos ânimos para a análise de objetos, os quais não são observados apenas como um em contraponto ao outro, mas também construídos dentro do próprio cruzamento, um junto com o outro e através dos outros. Werner e Zimmermann destacam três formas nas quais o cruzamento pode ser realizado: no próprio objeto, nos pontos de

ambos os reinos foi bastante similar. Entretanto, o contexto no qual Espagne escreve é de um mundo no qual o Nacionalismo já perdia sua força e influência, um mundo pós-Guerra Fria e, em termos étnicos e nacionais, desconstruído por ela. Os elementos levados em conta por Espagne para sua análise e proposições de suas metodologias, assim como para Bloch, estão diretamente ligados ao contexto em que ambos viveram e produziram.

${ }^{5}$ No caso de uma produção genuinamente brasileira sobre o tema, merece destaque a obra do historiador José D’Assunção Barros, professor do Programa de Pós-Graduação em História Comparada da UFRJ, com dois capítulos destinados às Histórias Interconectadas e à História Cruzada, em seu livro História Comparada, publicado em 2014 pela Editora Vozes. 
vista ou em escalas.

No primeiro exemplo, o cruzamento é a operação necessária para a construção do objeto a ser analisado. Neste caso, o caráter empírico da pesquisa é mais expressivo, pois a modalidade de análise do objeto está diretamente vinculada ao contexto histórico no qual este está inserido. (Werner e Zimmerman, 2003) Logo, o próprio objeto é construído a partir do período histórico trabalhado e suas particularidades devem ser respeitadas.

No segundo caso, a construção do objeto de pesquisa parte de um ponto de vista tanto empírico quanto epistemológico, posto que o ponto de vista adotado suscita diferentes tipos de cruzamentos. Um objeto pode ser analisado dentro de sua própria temporalidade ou a partir das influências que exerce em outro tempo histórico, por exemplo. O cruzamento histórico pode ocorrer tanto com relação ao objeto em diferentes temporalidades, quanto aos diferentes olhares num mesma temporalidade. (Werner e Zimmerman, 2003) Neste caso específico, observamos também que o cruzamento pode acontecer dentro de uma perspectiva diacrônica, analisando o objeto dentro de tempos históricos distintos. O cruzamento do ponto de vista epistemológico comporta também diferentes áreas do saber, múltiplos olhares acerca do mesmo objeto, incluindo perspectivas de campos como a história, ciências sociais, antropologia, linguística, filosofia, etc. ${ }^{6}$ Neste caso, o estudo demanda mais atenções, pois envolve não apenas a construção e o cruzamento do objeto em si, mas os olhares que se podem destinar a ele dentro de um mesmo tempo.

Já o terceiro caso, o cruzamento de escalas, traz à tona o debate do micro e do macro, instigando o pesquisador a repensar escalas pré-concebidas de análise, tais como as escalas nacionais. Como os autores definem no artigo, essa forma de cruzamento representa um "jogo de escalas", marcando os possíveis diferentes pontos de vista sobre o passado. Os objetos empíricos não são passíveis de uma única escala possível ou um único foco de compreensão do passado. Não se trata meramente de uma dicotomia entre micro e macro, mas dos diferentes espaços em que se circunscrevem as interações analisadas. (Werner e Zimmerman, 2003) Representa, portanto, novas propostas de escalas a serem analisadas dentro de um recorte temporal e geográfico, tornando possível atingir objetivos acadêmicos e intelectuais sem levar em conta recortes existentes.

A história cruzada parte do pressuposto, ainda, de que o cruzamento não se dá uma única vez em um único ponto e que os seus elementos envolvidos não são afetados da mesma forma. $\mathrm{Na}$ visão de Werner e Zimmermann

A história cruzada, por sua vez, interessa-se tanto por aquilo que o cruzamento pode produzir de novo e de inédito quanto pela maneira como ele afeta uma das partes "cruzadas", supondo que elas permanecem identificáveis, mesmo que alteradas. Aqui está um outro marcador da problemática do cruzamento. (Werner e Zimmerman, 2003)

Reiteramos que o cruzamento é um elemento-chave dentro da história cruzada. O enfoque nos objetos, contextos ou disciplinas cruzados dão o tom dessa modalidade de comparativismo histórico, pois ele produz novos contextos, novos objetos e novas formas culturais: tudo isto a partir das interseções, das conexões, dos encontros. As relações, interações e circulações demonstram, portanto, o caráter dinâmico do processo histórico. "Cruzar é também entrecruzar,

60 cruzamento do ponto de vista epistemológico aproxima-se do que Marcel Detienne em seu livro Comparar o incomparável chamou de campo de experimentação comparada. No entanto, na obra do historiador francês abordou a importância do diálogo entre os departamentos, a fim de que pesquisadores de áreas distintas analisem a partir dos pressupostos metodológicos de suas respectivas disciplinas. No caso da proposta de Werner e Zimmermann, um mesmo faria o cruzamento epistemológico. 
entrelaçar, ou seja, cruzar diversas vezes, segundo temporalidades eventualmente distanciadas". (Werner e Zimmerman, 2003) Dispor em forma de cruz implica também pensar em pontos de interseção. No cruzamento dos objetos, em temporalidades sincrônicas ou diacrônicas, tomamos ciência das trajetórias, das formas e dos conteúdos e de suas respectivas permanências e rupturas. Somando-se ao cruzamento, outro ponto em que a história cruzada merece particularmente destaque é na maneira como ela analisa e aborda os fenômenos de interação.

Elas [operações] podem igualmente se cruzar e engendrar dinâmicas específicas, por meio de diferentes tipos de inter-relações. Todos estes casos escapam a uma análise que estabelece simplesmente uma relação entre um ponto de partida e um ponto de chegada. Estudar tais diferentes configurações convida a conceber quadros teóricos e instrumentos metodológicos que permitem abordar fenômenos de interação, implicando uma pluralidade de direções e uma multiplicidade de efeitos. A nosso ver, a figura do cruzamento oferece a possibilidade de pensar tais configurações. (Werner e Zimmerman, 2003)

A história cruzada extrapola os limites das transferências, proposta por Espagne. O objetivo não é apenas observar as influências para compreender o impacto que estas causam em determinado grupo social, levando em consideração um ponto de partida e outro de chegada, mas o de levar a análise ao nível de quais são as novas engrenagens construídas a partir dessa interação e de que forma elas foram construídas. Tal premissa nos auxilia no entendimento, por exemplo, de como as interações entre grupos distintos corrobora para a formação de elementos novos elementos culturais e não apenas um amálgama deles.

Destarte, podemos afirmar que, se a história das transferências foca, como o próprio nome diz, na transferência - e consequentemente em influências - de uma cultura para outra, ao passo que a história cruzada busca analisar de que maneira essas transferências são construídas, num processo complexo de relação e interação nunca completo ou acabado, permite compreender de forma mais satisfatória a complexidade de um mundo plural em movimento. O produto final, resultado de uma interação, analisado a partir do cruzamento, não é um objeto " $\mathrm{A}$ " que sofreu influência de um objeto "B", e sim, um objeto "C", novo em suas especificidades, com suas relações e características próprias.

O avanço que a história cruzada representa dentro do comparativismo histórico é substancial. Novas unidades de comparação são selecionadas, saindo da esfera do Estado Nacional - e da história das transferências. (Marjanen, 2009) Ultrapassa ambos. Olhando sob essa perspectiva, a história cruzada convida o pesquisador a investigar e indagar melhor outros aspectos presentes na história comparada, que não passam apenas pelos pressupostos da história das transferências, os quais privilegiam as influências causadas por uma cultura em outra, nem consideram a órbita a partir das estruturas político-administrativas que envolvem a organização do Estado enquanto uma categoria passível de comparação.

Em relação à história comparada, Werner e Zimmermann destacam ainda cinco pontos, os quais a história cruzada contemplaria frente a outras modalidades de comparativismo histórico: (1) a posição do observador com relação ao objeto de estudo; (2) os níveis de comparação; (3) a definição do objeto de comparação; (4) as relações entre sincronia e diacronia; (5) a interação entre os objetos de comparação. Cabe destacar, entretanto, que tais reflexões não correspondem a prerrogativas exclusivas da história cruzada. Dentro de todo saber historiográfico, o pesquisador da área de história deve ter esse tipo de preocupação quanto à neutralidade com relação ao seu objeto de estudo, a definir comparáveis possíveis e não forçosas - para não cair no anacronismo - e a 
trabalhar com os tempos sincrônico e diacrônico.

O próprio subtítulo do capítulo dos autores - entre a empiria e a reflexividade - levanta duas outras questões importantes. A primeira delas reside na necessidade de ações concretas no recorte do objeto de pesquisa, algo a ser realizado na investigação empírica. Os objetos não podem ser delimitados a priori, mas como parte de um processo estruturante, influenciados pelas interferências recíprocas entre estrutura e ação. (Werner e Zimmerman, 2003)

O segundo aspecto é a reflexividade. Convidado a considerar e rever seus próprios conceitos e como fruto de processos de cruzamento complexos, Werner e Zimmermann consideram estes como fruto das tradições nacionais e disciplinares as quais os pesquisadores estão inseridos. O conceito não existe por si só, pois está vinculado a uma teia de relações nas quais está inserido e, ao abordá-lo, a história cruzada busca evidenciar os meandros por detrás desses entrecruzamentos.

\section{Considerações finais}

Como pudemos observar nas discussões feitas acerca de história das transferências e história cruzada, o debate ainda está muito centrado na Europa, sobretudo na Alemanha e na França. O artigo de Marjanen, em língua inglesa, é uma exceção dentro deste campo de estudos. Kaelble propôs ao final de seu capítulo, a expansão desse debate para fora desse nicho e que "deveria ser transmitido mais fortemente às disciplinas vizinhas", abrindo-se também ao espaço anglo-saxão, da língua espanhola e do sudeste asiático. (Kaelble, 2004)

Ao longo de quase um século, a história comparada passou por muitas análises, revisões e reorganizações, saindo do campo de mero ato de comparar dois contextos distintos para diretrizes enquanto método e um campo historiográfico fértil ao pesquisador.

No caso específico das histórias conectadas, muito embora não haja padronização no vocabulário acadêmico, observamos uma nova tendência no que tange à construção e à análise de objetos passíveis de comparação, muitas das vezes os quais são construídos a partir da interação e do contato entre grupos culturais distintos. A experiência e os intercâmbios culturais representam nela, portanto, um dos elementos centrais no recorte do objeto.

No modelo proposto pela história cruzada, as reflexões propostas por Werner e Zimmermann dão novo fôlego ao comparativismo histórico, na medida em que, a partir do cruzamento, propõem rever os paradigmas que edificaram a própria história comparada enquanto campo historiográfico. Seja na construção do objeto de pesquisa, nos pontos de vista empíricos e epistemológicos ou nas escalas, o cruzamento corresponde a uma ação instigante para o pesquisador, ao convidá-lo a rever seu próprio fazer historiográfico. Destarte, a história cruzada desafia o pesquisador constantemente a questionar a historicidade de seus objetos e conceitos, articulando-os com sua temporalidade.

\section{Referências}

BARROS, José D’Assunção. História comparada - um novo modo de ver e fazer a história. In: Revista de História Comparada. Volume 1, número 1, jun./2007. p. 1-30.

Histórias Cruzadas - considerações sobre uma nova modalidade baseada nos procedimentos relacionais. In: Anos 90, Porto Alegre, v. 21, n. 40, p. 277-310, dez. 2014. 
BLOCH, Marc. História e historiadores: textos reunidos por Étienne Bloch. Lisboa: Teorema, 1998. CARDOSO, Ciro F.S. e BRIGNOLI, Hector P. Os métodos da história: introdução aos problemas, métodos e técnicas da história demográfica, econômica e social. Rio de Janeiro: Edições Graal, 1981.

CHARLE, Christophe. Comparaisons et transferts en histoire culturelle de l'Europe. Quelques réflexions à propos de recherches récentes. In: Les cahiers Irice, 2010/1 n5, p. 51-73.

DETIENNE, Marcel. Comparar o incomparável. São Paulo: Ideias e Letras, 2004.

ESPAGNE, Michel. Les transferts culturels.In: H-Soz-u-Kult 19.01.2005, http://hsozkult.geschichte.hu-berlin.de/forum/2005-01-002.

Sobre os limites do comparatismo em história cultural. In: ponto-e-vírgula, 13: 91-108, 2013. Tradução de Guilherme Simões Gomes Júnior.

HANNICK, J.-M. Simples réflexions sur I'Histoire Comparée.(Louvain-la-Neuve) - Número 2 - julhodezembro de 2001. Disponível na internet em http:bcs.fltr.ucl.ac.be/FE/02. Acesso em 05/01/2005. [tradução de Regina Maria da Cunha Bustamante]

HAUPT, Heinz-Gerner. O lento surgimento de uma História Comparada. In: JULIA, Dominique e BOUTIER, Jean. Passados recompostos: campos e canteiros da história. Rio de Janeiro: Editora UFRJ, 1998.

KAELBLE, Hartmut. O Debate sobre a Comparação e a Transferência: e agora? Tradução de Álvaro Alfredo Bragança Júnior. Disponivel em <https://geschichte-transnational.clio--online.net/forum/id=547\&type=artikle $>$. Texto original de 21/21/2004.

KOCKA, Jürgen. Comparison and beyond. History and Theory 42: 39-44, feb. 2003. [tradução Maria Elisa da Cunha Bustamante].

MARJANEN, Jani. Undercoming methodological nationalism: Histoirecroisée of concepts as transnational history. In.: ALBERT, Mathias et al. TransnationalPoliticalSpaces: Agents - Structures Encounters. Frankfurt/New York: Campus, 2009. p. 239-263.

RÜSEN, Jörn. Historiografia comparativa intercultural. In: MALERBA, Jurandir (org.). A história escrita: teoria e história da historiografia. São Paulo: Contexto, 2006.

SKOCPOL, Theda and SOMERS, Margaret. The Uses of Comparative History in Macrosocial Inquiry. In: Comparative Studies in Society and History, Vol. 22, No.2 (Apr., 1980), 174-197.

THEML, Neyde e BUSTAMENTE, Regina Maria da Cunha. História Comparada: Olhares Plurais. In: Revista de História Comparada, volume 1, número 1, jun./2007.

WERNER, Michael e ZIMMERMANN, Bénédicte. Pensar a história cruzada: entre a empiria e a reflexividade. In: Textos de História, vol. 11, $n^{\circ}$ 1/ 2, 2003. p. 89-127.

\section{Artigo recebido em: 20/02/2019}

Artigo aceito em: 28/05/2019 